\title{
Enhancement of Ascorbic Acid in Processed Yellow Cultivar Mung Bean Seeds
}

Thippeswamy T.G ${ }^{1}$, Lalitha Junna ${ }^{2}$, Manohar Shinde ${ }^{*}$

${ }^{1}$ Department of Studies and Research in Biochemistry, Tumkur University, Tumakuru, Karnataka, India.

${ }^{2}$ Department of Biochemistry, Gulbarga University, Kalaburgi, Karnataka, India.

\section{Abstract}

Ascorbic acid is an excellent reducing power and antioxidant metabolite that participates in various biochemical reactions like metabolism of tyrosine, tryptophan and catecholamines, serotonin, biosynthesis of nitric oxide (NO), protects DNA and proteins from potential free radical damage. For humans, it is an essential vitamin which must be supplied through exogenous sources and diet, whose latent and chronic deficiency causes various patho-physiological, non-communicable, degenerative and metabolic complications whereas, acute deficiency was implicated with vascular damage, tissue damage and scurvy. The purpose of the study is to enhance ascorbic acid content in commonly eaten food grains as fruits and vegetables, which are good sources of ascorbic acid, due to their soaring prices have become unaffordable for the people of low income groups. This is the first report wherein, we have made an attempt to enhance the ascorbic acid content of a yellow colored mung bean cultivar by simple house-hold processing technique. The ascorbic acid content of $100 \mathrm{~g}$ of dry seeds and $12 \mathrm{hr}$ rehydrated seeds were estimated to $27 \mathrm{mg}$ whereas, the germinating seeds have shown an increase in the ascorbic acid content to $114 \mathrm{mg}$ per $100 \mathrm{~g}$ seeds.. The processing of mung bean seeds by sprouting has been shown to increase the ascorbic acid content by 4.2 fold as compared to that of unprocessed dry seeds. The ascorbic acid content of $100 \mathrm{~g}$ mung bean seeds was found to be twice the value of recommended dietary allowance, thus mung bean sprouts of yellow cultivar seeds appears to be an excellent source to mitigate various pathologies.

Keywords: Ascorbic acid; Processing; Germination; Yellow Cultivar Mung Bean.

\section{*Corresponding Author:}

Manohar Shinde,

Department of Studies and Research in Biochemistry, Tumkur University, Tumakuru-572103, Karnataka, India.

Tel: +91-9449157975

E-mail: drsmanohar@gmail.com

Received: November 08, 2015

Accepted: December 17, 2015

Published: December 18, 2015

Citation: Thippeswamy T.G, Lalitha J, Shinde M (2015) Enhancement of Ascorbic Acid in Processed Yellow Cultivar Mung Bean Seeds. Int J Food Sci Nutr Diet. 04(7), 253-257. doi: http://dx.doi.org/10.19070/23263350-1500045

Copyright: Shinde $\mathbf{M}^{\odot}$ 2015. This is an open-access article distributed under the terms of the Creative Commons Attribution License, which permits unrestricted use, distribution and reproduction in any medium, provided the original author and source are credited.

\section{Introduction}

Mung bean, Vigna radiata (L.) is an important food legume grown in south, east and south-east Asia, which contributes to about $90 \%$ of the world's mung bean produce and also grown and consumed in Europe, Australia and USA. It is the third major edible legume seed, next only to chick pea and cow pea both in its production and consumption pattern. It supplements micronutrients, minerals and easily digestible, good quality proteins to the largely cereal-based diets that contribute, significantly to a healthy and balanced diet for the people belonging to low economic groups [1-3]. Mung beans are good source of proteins, carbohydrates and minerals but, are marginal sources of vitamins. They are cooked fresh or dry and can be eaten whole or made into flour, soups, porridge, snacks, bread, noodles and ice-cream. One such vitamin is ascorbic acid which has been reported to be present in stored mung bean at concentrations of $0 \mathrm{mg}$ to $11.9 \mathrm{mg}$ per $100 \mathrm{gram}$ of dry mung beans [4-9, 11-14]. Ascorbic acid is an essential water soluble vitamin that is vital for the growth, maintainence and reproduction [15-18] of animals including humans. Most animals are able to biosynthesis required quantities of ascorbic acid endogenously, humans and some primates are required to obtain this metabolite through exogenous sources for they have lost this capability and became ascorbic acid defficient as a result of series of inactivating mutations that were estimated to have occurred 40 million years ago in the gene encoding L-gulonolactone oxidase, a key enzyme of ascorbic aicd biosynthesis pathway [19, 20]. Ascorbic acid is an exquicitely important and essential antioxidant metabolite with diverse functionalities, acute lack of ascorbic acid leads to scurvy, manifest by blood vessel fragility, connective tissue damage, fatigue and ultimately death. It is involved in the biosynthesis and maintenance of collagen [21, 22] steroid and peptide hormones [23, 24], L-carnitine, conversion of dopamine to nor-epinephrine, and under physiological conditions it is reported to quench potentially damaging free radicals [25] thus prevent oxidation of biomolecules [26, 27]. At adequate to high dosage it is reported to trigger immunostimulation, anti-inflammatory response and also decrease the levels of inflammatory cytokines IL- $1 \alpha$, IL-2, IL- $8, \mathrm{TNF}-\alpha$, chemokine and C-reactive protein in cancer patients and the people with rheumatoid arthritis, deffi- 
ciency of which causes manyfold health implications like scurvy, bleeding gums, reactive oxygen species (ROS) and reactive nitrogen species (RNS) mediated DNA and protein damage, immunecompromization, inflammation, stress and degenerative diseases [28]. The significance of ascorbic acid in human nutrition is that, it is put at the cross road in metabolism, and disease pathophysiology. Body of evidence suggest that continual dietary inadequacy of ascorbic acid leads to hypercholesteremia, anaemia, inflammation, ulcers which could be reverted by consuming ascorbic aicd rich foods. It is an important antioxidant with exceptionally good reducing power, which is helpful in reducing ferric to ferrous state of iron for its maximum bioavailability. The present investigation deals with the processing method for substantial increase in the ascorbic acid content of a new variety yellow colored mung bean cultivar. To our knowledge this is the first report concerning the detection and enhancement of ascorbic acid in yellow cultivar mung bean seeds.

\section{Materials and Methods}

\section{Material}

The Mung bean sample designated ALM4 was kind gift from Prof. J. Lalitha, Department of Biochemistry, Gulbarga University, Kalaburgi, India.

\section{Chemicals}

The chemicals used in the present study were of analytical grade and of highest purity. L-Ascorbic acid, 2.4 dinitrophenylhydrazine, trichloroacetic acid, thiourea, copper sulphate and sulfuric acid were procured from s.d. fine chemical Ltd. India.

\section{Germination conditions}

The seeds were manually cleaned and stored in cool and dark place. The seeds were washed with tap water and soaked in distilled water $(1: 9 \mathrm{w} / \mathrm{v})$ for $12 \mathrm{hr}$ and the excess water was drained. The soaked seeds were further germinated for different time periods by traditional method wherein, the seeds were tied in a fourfolded moistened white cotton cloth and were incubated at room temperature $\left(16\right.$ to $\left.28^{\circ} \mathrm{C}\right)$ in prevailing light and dark conditions during day and night periods respectively.

\section{Extraction}

The extraction of ascorbic acid from the dry samples and processed samples were carried out under cold conditions in an ice bath by the method as described by Schaffert and Kingsley, 1955 [29]. Briefly, the samples were homoginized using a pestle and mortar to a fine paste by the addition of minimal volume of $5 \%$ trichloroacetic acid (TCA) and the ascorbic acid was extracted by the addition of $5 \%$ TCA $(1: 50 \mathrm{w} / \mathrm{v})$ over a period of $30 \mathrm{~min}$ while vortexing for two minutes after every $10 \mathrm{~min}$ duration. The clear supernatant containing ascorbic acid was recovered by centrifugation for $15 \mathrm{~min}$ at $10000 \mathrm{rpm}$ and $4^{\circ} \mathrm{C}$.

\section{Estimation of ascorbic acid}

Preparation of standard graph: Ascorbic acid, at concentrations ranging from 8 to $40 \mu \mathrm{g} / \mathrm{ml}$ were pipetted in a series of tubes, volume was adjusted to $1 \mathrm{ml}$ by the addition of required amount of 5\% TCA solution. A-1 ml of DNPH reagent was added to all the tubes and the tubes were placed in a boiling water bath for $10 \mathrm{~min}$. The test tubes were cooled under running tap and then the contents of the tube chilled using ice bath following this, a $5 \mathrm{ml}$ of ice cold $85 \%$ sulfuric acid was added slowly through the walls of the tubes. The contents of the tubes were cooled and the color developed was read at $520 \mathrm{~nm}$ in a spectrophotometer (uv/vis spectrophotometer, ELICO-SL 159).

Estimation of ascorbic acid in sample: The extracts of the dry and processed mung been seeds were clarified by centrifugation at $10000 \mathrm{rpm}$ for $10 \mathrm{~min}$ and $4^{\circ} \mathrm{C}$. A $1 \mathrm{ml}$ of suitably diluted clear supernatant of the extract was used for the estimation of ascorbic acid as shown above and mg ascorbic acid per $100 \mathrm{~g}$ seeds is represented as $\mathrm{mg}^{\%} \%$. The results of the estimations are the representatives of average values of three repeat experiments.

\section{Results and Discussion}

\section{Results}

Preparation of Standard graph: The estimation of standard ascorbic acid was carried out at concentrations ranging from 0 to $40 \mu \mathrm{g} / \mathrm{ml}$. The result of the estimation of standard ascorbic acid was plotted and graph of absorption $\mathrm{v} / \mathrm{s}$ concentration of ascorbic acid showing linear regression, $\mathrm{r}^{2}-0.996$ is shown in Figure 1.

Ascorbic acid in dry seeds and rehydrated seeds: The concentration of ascorbic acid in stored, dry mung bean seeds and rehydrated mung bean seeds after soaking for different time period is shown in Table 1 and Figure 2. The concentrations of ascorbic acid in dry and rehydrated mung bean seeds were found to be $27.25 \mathrm{mg}$ and $27.12 \mathrm{mg}$ respectively per 100 gram seeds.

Ascorbic acid in germinating seeds: The mung bean seeds were processed by germination over a period of 7 days as described in material and methods. The concentration of ascorbic acid in the germinating mung bean seeds is shown in Table 1 and Figure 2. The ascorbic acid content of germinating mung bean seeds were estimated to $51.08 \mathrm{mg}, 79.06 \mathrm{mg}, 86.94 \mathrm{mg}, 102.4 \mathrm{mg}$, at $6 \mathrm{hr}, 12 \mathrm{hr}, 18 \mathrm{hr}$ and $24 \mathrm{hr}$ of germination of mung bean seeds respectively per $100 \mathrm{~g}$ dry seeds. The changes in the ascorbic acid content was further monitored colorimetrically in the extracts of germinating seeds after germination for 2 to 7 days and was found to be $101.4,102.4,114.2,111.4,113$ and $87.06 \mathrm{mg}$ per $100 \mathrm{~g}$ seeds respectively on day 2 through day 7 .

\section{Discussion}

One of the most difficult problem confronting globally in the present time is that the limitation of agricaultural research in providing suitable solutions to the rain-fed land holders for production of vegetables and fruits sufficient to meet the nutritional needs of common man. Vegetables and fruits are rich in many essential vitamins, minerals and antioxidants, thus, considered as protective foods as they afford protection against many metabolic and dietary deficiency diseases, and also against non-communicable and degenerative diseases. The association with the reduced risk of cardio-vascular disease with high consumption of vegetables and fruits is attributed in part due to their high content of ascorbic acid and vitamin E, as the compelling evidence suggest that the onset and progression of the disease is attributed to oxidative damage due to ROS and RNS [30-33]. The surge in the prices of vegetables and fruits is an economical barrier, which 
Figure 1. Standard graph of ascorbic acid.

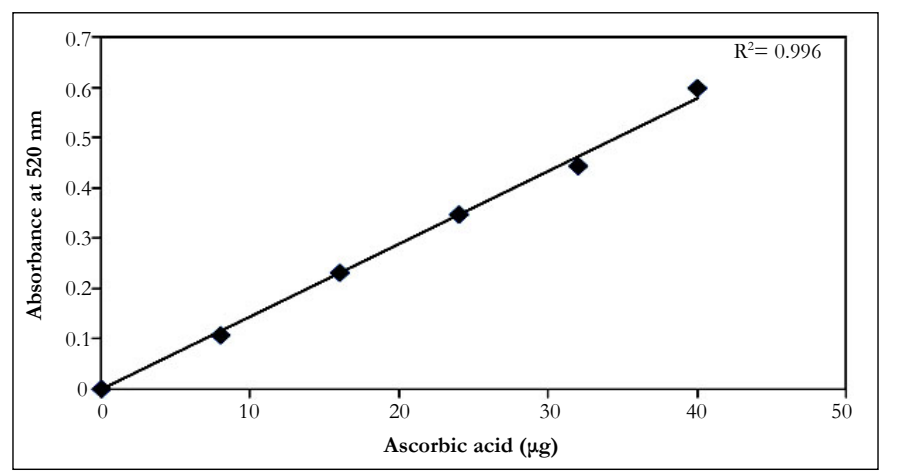

Table 1. Ascorbic acid (AsA) in germinating yellow cultivar mung bean seeds.

\begin{tabular}{|c|c|}
\hline Day & AsA $\mathbf{( m g} / \mathbf{1 0 0 g})$ \\
\hline Dry & 27.25 \\
\hline 0 hr & 27.12 \\
\hline $6 \mathrm{hr}$ & 51.08 \\
\hline $12 \mathrm{hr}$ & 79.06 \\
\hline $18 \mathrm{hr}$ & 86.94 \\
\hline Day 1 & 89.52 \\
\hline Day 2 & 101.49 \\
\hline Day 3 & 102.47 \\
\hline Day 4 & 114.23 \\
\hline Day 5 & 111.44 \\
\hline Day 6 & 113.03 \\
\hline Day 7 & 87.06 \\
\hline
\end{tabular}

Figure 2. Ascorbic acid content in germinating yellow cultivar mung bean seeds.

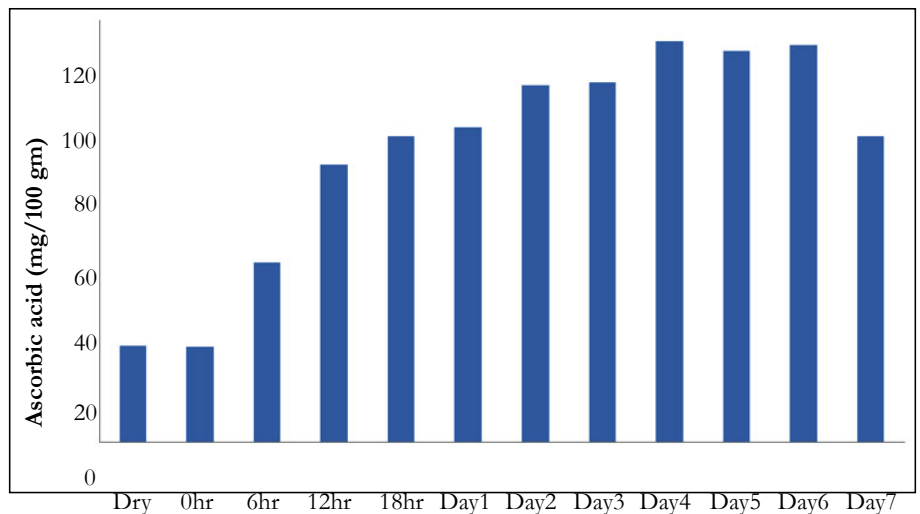

limits the consumption of protective foods for the larger population in rural areas and also among low and middle income groups dwelling in urban areas. This has forced the people to subsists on the refined legumes, cereals, and fat which, may not supply all the essential nutrients in required quantity. Legumes are good sources of proteins, carbohydrates and minerals but are fair sources of vitamins. The vitamin contents of some of the pulses have been shown to increase by processing techniques and one such method is germination. Plethora of information is available on the health benefits of ascorbic acid and also on the improvement of ascorbic acid and other vitamins, antioxidants and removal of antinutrients from variety of foods by simple processingg techniques $[4-9,11-15,21,30-33,37,38]$.

The recommended dietary intake of ascorbic acid is largely based on the amount required for the biosynthesis and maintenance of collagen and for the biosynthesis of some hormones. Ascorbic acid, due to its powerful antioxidant activity, protects lipids from oxidation and sequesters free radicals, thus considered as boon for the people who are suffering from diabetes, age related degenerative diseases and the people subjected to oxidative stress. Taking into consideration, the poor bioavailability, instability and excretion of ascorbic acid, relatively high levels of this vitamin must be maintained in the body because, low serum levels of ascorbic acid may have serious health implications and is particularly relevant to the onset of age related problems and degenerative diseases [34]. Moreover, wealth of information from laboratory research and epidemiological data evidences that the ascorbic acid is efficient against certain cancers like cancer of lung, cervix, colon, rectum, pancreas and breast and also implicated in vasodilation in patients with cardiovascular disease (CVD) and coronary risk $[35,36]$. Furthermore, ascorbic acid and vitamin E can interact synergistically in protection against the onset of CVD; moreover, ascorbic acid regenerates vitamin E [37] and is reported to en- 
hance eNOS, superoxide dismutase, regulate NO by attenuating NADPH oxidase activity, thus inhibit ROS and RNS which are implicated in CVD [38].

In the present study, the screening of different stored dry legumes, cereals and oil seeds for their ascorbic acid content revealed the presence of significantly high initial concentration of ascorbic acid ( $27.25 \mathrm{mg} / 100 \mathrm{~g}$ whole seeds) in yellow cultivar mung bean seeds ALM4. The studies leading to the determination of ascorbic acid content in stored dry mung bean seeds by various investigators lead to an observation that the asorbic acid is distributed in cereals and legumes, however at marginal levels. The reports on the ascorbic acid content in mung bean and other legumes are rather conflicting for example, Moriyama and Oba, 2008 [4]; Maneemegalai and Nandkumar, 2011 [5] and Guo et al, 2012 [6] reported the presence of $6.5 \mathrm{mg}$ of total ascorbic acid, 8.8 and $11.69 \mathrm{mg}$ ascorbic acid per $100 \mathrm{~g}$ dry mung bean seeds respectively, on the contarary Gallup and Redder, 1943 [7], Sattar et al., 1989 [8], Shah et al, 2011 [9], Masood et al., 2014 [10] and Haung et al., 2014 [11] reported the absence of ascorbic acid in dry mung bean seeds. Fernandez-Oroczo et al., 2008 [12] have reported the presence of $1.9 \mathrm{mg}^{\%}$ of ascorbic acid in raw mung bean seeds. Abdulla and Baldwin, 1984 [13] and Plaza et al., 2003 [14] have demonstrated the ascorbic acid content in soy beans and mung beans. Fernandez-Orarp 2008 [12], observed a steep increase in the ascorbic acid content of germinating mung bean from 1.9 $\mathrm{mg}^{0} \%$ in raw seeds to $9.07 \mathrm{mg}^{0} \%$ after seven days of germination but, the same authors did not detect ascorbic acid content in raw seeds or germinating soyabean seeds whereas, Plaza et al. 2003 [13] detected $9.9 \mathrm{mg}^{\%} \% 31.6 \mathrm{mg}^{0} \%$ and $8.1 \mathrm{mg}^{0} \% 82.6 \mathrm{mg}^{\%}$ in dry and germinated soyabean seeds and alfalfa seeds respectively. Our results on the investigation of ascorbic acid content in dry, stored yellow cultivar mung bean ALM4 showed $27.25 \mathrm{mg}$ ascorbic acid per 100 grams of seeds, which is 2.3 to 27 times higher than that of the earlier reported values.

Germination improves the texture, palatability, antioxidant capacity and general nutritional status of legumes and cereals as it is compared to that of the dry seeds. Germination also was reported to be associated with increase of vitamin concentrations and bioavailability of minerals [39]. Many investigators have reported their findings on the improvement of ascorbic acid content in germinating green mung bean seeds of different varieties. Our results on the investigations of ascorbic acid in germinating mung bean seeds are in accordance with earlier reports. Moriyama and Oba, 2008 [4] reported 4.5 times increase in the ascorbic acid content of $16 \mathrm{hr}$ rehydrated mung bean seeds $(29.2 \mathrm{mg} / 100 \mathrm{~g}$ seeds $)$ as compared to stored dry seeds $(6.5 \mathrm{mg} / 100 \mathrm{~g}$ seeds). Maneemegalai and Nandkumar, 2011 [5] estimated $8.8 \mathrm{mg}$ of ascorbic acid in $100 \mathrm{~g}$ of stored, dry green mung bean seeds which was shown to increase to $11.8 \mathrm{mg}, 7.6 \mathrm{mg}$ and $20.6 \mathrm{mg}$ after 24,48 and 72 hours of germination. Guo et al., 2012 [6], found $11.69 \mathrm{mg}$ of ascorbic acid in dry green mung bean seeds, which increased to 43 $\mathrm{mg}, 95 \mathrm{mg}, 140 \mathrm{mg}$, and $155 \mathrm{mg}$ after $24 \mathrm{hr}, 48 \mathrm{hr}, 72 \mathrm{hr}$, and 96 hr of germination and reached maximum to $285 \mathrm{mg}$ after 8 days. Some of the investigators could not find the detectable levels of ascorbic acid but, reported appreciable increase in ascorbic acid after germination over a period of time. The stored green mung bean seeds of dwarf variety did not show the presence of ascorbic acid whereas, a steep increase in the ascorbic acid content to $128 \mathrm{mg}$ per $100 \mathrm{~g}$ of seeds occurred after 4 days of germination [[7] Gallup and Redder 1943]. Sattar et al, 1989 [8], reported the absence of ascorbic acid in dry mung bean seeds but, found at concentrations of 16 and $15 \mathrm{mg}, 33$ and $47 \mathrm{mg}, 29$ and $25 \mathrm{mg}$, 26 and $21 \mathrm{mg}, 16$ and $26 \mathrm{mg}$ and 21 and $21 \mathrm{mg}$ after germination for 1 through 6 days at ambient $\left(20^{\circ} \mathrm{C}\right.$ to $\left.32^{\circ} \mathrm{C}\right)$ and $20^{\circ} \mathrm{C}$ respectively and observed a maximum increase after two days of germination further it was gradually decreased. Recently, similar observations on the ascorbic acid content of dry and germinating green mung bean seeds of different varieties were also made by different investigators [9-11]. Shah et al [9], used Ramzan and NM-98 variety, Masood et al [10], and Haung et al [11] used green Mung bean, Var. KM-1 and Mung bean var Emrald respectively. All the four varieties did not show detectable levels of ascorbic acid in stored, dry seeds however, germination had a profound effect on the ascorbic acid content. Shah et al [9], observed 13.7 to $23.2 \mathrm{mg}$ ascorbic acid per $100 \mathrm{~g}$ dried sprouts after 24 to $96 \mathrm{hr}$ of germination in mung bean var. Ramzan and NM-98. Masood et al [10] reported 4.67, 18.17, 31, 33.83 and $37 \mathrm{mg}$ of ascorbic acid and Haung et al [11], reported 3.38, 3.34, 4.79, 3.73, $4.22 \mathrm{mg}$ of ascorbic acid per $100 \mathrm{gm}$ dry seeds after 1 through 6 days of germination. Fernandez-Oroczo et al., [12] detected of $1.9 \mathrm{mg}$ of ascorbic acid in raw mung bean seeds and shown to increase the ascorbic acid content to 2.82, 7.02, 7.61, $9.07 \mathrm{mg}$ after 2, 3, 4 and 5 days of germination respectively. Germination increased the concentration of ascorbic acid in mung bean seeds but, the same processing technique did not show any increase in ascorbic acid content of soya bean seeds [12].

In the present study, we have investigated the ascorbic acid content in germinating seeds of yellow cultivar mung beans. Although similar concentrations of ascorbic acid observed in stored, dry yellow cultivar mung bean seeds and $12 \mathrm{~h}$ rehydrated seeds however, processing by simple germination has brought about appreciable changes in the ascorbic acid content of these seeds in time dependent manner (Table1 and Figure 2). An initial concentration of $27.25 \mathrm{mg}$ of ascorbic acid in the dry seeds increased to $52 \mathrm{mg}$, $79 \mathrm{mg}, 85 \mathrm{mg}$ and $90 \mathrm{mg}$ per $100 \mathrm{~g}$ of seeds after 6,12, 18 and $24 \mathrm{hr}$ of germination respectively. Further germination of seeds from day 2 through day 7 showed marginal increase in the ascorbic acid concentration (102 $\mathrm{mg}$ after day 2 and 3) and reached peak $(114 \mathrm{mg})$ on day 4 and remained same through day 6 and decreased to $87 \mathrm{mg}$ per $100 \mathrm{gm}$ seeds on day 7 .

It is evident from the results that the increase in the accumulation of ascorbic acid concentration in the germinating mung bean ALM4 seeds were concomittantly associated with the increase in germination time and ascorbic acid concentration reached the recommended dietary allowance (RDA) value of ascorbic acid within $6 \mathrm{hr}$ and twice the RDA value within $12 \mathrm{hr}$ of germination. Our results showed substantial increase in the concentration of ascorbic acid in the seeds processed by germination and are in agreement with the earlier studies. The literature on the enhancement of ascorbic acid in germinating mung bean seeds suggest that Guo et al [6], reported the highest concentration of ascorbic acid accumulation in germinating mung bean sprouts as compared to that of other reports presented by different investigators. They have detected the accumulation of $285 \mathrm{mg}$ of ascorbic acid after 8 days of germination, which is the highest concentration reported in literature. Though Guo et al [6], reported highest ascorbic acid in germinating mung bean seeds, we are of an opinion that our results on accumulation of ascorbic acid in germinating yellow mung bean cultivars are superior as compared to earlier reports. The significance is that the yellow cultivars showed $27.25 \mathrm{mg}$ ascorbic acid per $100 \mathrm{gm}$ stored, dry seeds as compared to that of highest reported $11.9 \mathrm{mg}$ per $100 \mathrm{~g}$ 
stored, dry seeds. Further a substantial increase in the accumulation of ascorbic acid in the sprouts within $18 \mathrm{hr}$ of germination like, $52 \mathrm{mg}$ per $100 \mathrm{gm}$ seeds at initial $6 \mathrm{hr}$ of germination and 79 $\mathrm{mg}$ and $87 \mathrm{mg}$ of at 12 and $18 \mathrm{hr}$ of germination (Figure 2). Our results are highly significant for both house hold sprouting and also for commercial applications because, accumulation of high levels of ascorbic acid in the sprouts within shortest germination time is important for its consumtion as protective food, both aesthetically and microbiologically. This is one of the important parameters to develop safer and appealing processed foods. There is a great demand for processing methods and grain varieties that improves general nutrition and phytochemical status quickly and rapidly so as to minimize microbial contamination for consumer safety.

\section{Conclusion}

Yellow cultivar mung bean seeds ALM4 showed 3.8 to 4.2 fold improvement of ascorbic acid content in their sprouts. Thus, there is a possibility of commercial exploration for the development of protective foods using sprouts of yellow cultivar mung bean ALM4, as they accumulate high levels of ascorbic acid within short germination time. Food processing by germination emerged as an economically viable method that doesn't attract expensive equipment to enhance ascorbic acid content in mung bean seeds. Therefore, the mung bean sprouts can be included in the meal to maintain high levels of ascorbic acid in the body, which is reported to prevent scurvy, degenerative diseases and also mitigate gastric ulcers.

\section{Acknowledgement and Declarations}

TGT and MS are thankful to Tumkur University for providing research facility. The authors have no conflict of interest for publication of this research work.

\section{References}

[1]. Shanmugasundaram S, Keatinge JDH, Hughes JDA (2009) The mung bean transformation: Diversifying crops, defeating malnutrition. IFPRI discussion paper 922.

[2]. Shanmugasundaram S, Keatinge JDH, Hughes J (2009) Counting on beans: mung bean improvement in Asia. In Millions fed: Proven successes in agricultural development. IFPRI: Washington DC

[3]. Bains TS, Brar JS, Singh G, Sekhon HS, Kumar BS (2006) Improving income and nutrition by incorporating mung bean in cereal fallows in Indo Gangetice Plains of South Asia. AVDRC Publication, Shanhua, Taiwan.

[4]. Moriyama M, Oba K (2008) Comparative study on vitamin C contents of food legume seeds. J Nutr Sci Vitaminol 54(1): 1-6.

[5]. Maneemegalai S, Nandakumar S (2011) Biochemical studies on the germinated seeds of Vigna radiate (L.) R. Wilczek, Vignamungo (L.) Hepper and Pennisetumtyphoides (Burm f.) Stapf and CE Hubb. Int J Agric Res 6 (7): 601-606.

[6]. Guo X, Li T, Tang K, Liu RH (2012) Effect of germination on phytochemical profiles and antioxidant activity of mung bean sprouts (Vigna radiata). J Agric Food Chem 60(44): 11050-11055.

[7]. Gallup WD, Reder RE (1943) Sprouted cowpeas as a source of protein and vitamins. Proceedings of the Oklahoma Academy of Science 53-55.

[8]. Sattar A, Durrani SK, Mahmood F, Ahmad A, Khan I (1989) Effect of soaking and germination temperatures on selected nutrients and antinutrients of mungbean. Food Chem 34(2): 111-120.

[9]. Shah SA, Zeb A, Masood T, Noreen N, Abbas SJ, et al. (2011) Effects of sprouting time on biochemical and nutritional qualities of mung bean varieties. African J Agric Res 6(22): 5091-5098.

[10]. Masood T, Shah HU, Zeb A (2014) Effect of sprouting time on proximate composition and ascorbic acid level of mung bean (Vigna radiate L.) and chickpea (Cicerarietinum L.) Seeds. J Animal Plant Sci 24(3): 850-859.

[11]. Huang X, Cai W, Xu B (2014) Kinetic changes of nutrients and antioxidant capacities of germinated soybean (Glycine max L.) and mung bean (Vignaradiata L.) with germination time. Food Chem 143: 268-276.

[12]. Fernandez-Orozco R, Frias J, Zielinski H, Piskula MK, Kozlowska H, et al. (2008) Kinetic study of the antioxidant compounds and antioxidant capacity during germination of Vigna radiate $c v$. emmerald, Glycine max cv. jutro and Glycine max cv. merit. Food Chem 111: 622-630.

[13]. Abdullah A, Baldwin RE (1984) Mineral and vitamin contents of seeds and sprouts of newly available small-seeded soybeans and market samples of mung beans. J Food Sci 49(2): 656-657.

[14]. Plaza L, de Ancos B , Cano MP (2003) Nutritional and health-related compounds in sprouts and seeds of soybean (Glycine max), wheat (Triticum aestivum.L) and alfalfa (Medicago sativa) treated by a new drying method. Eur Food Res Technol 216(2): 138-144.

[15]. Harris WA, Harden TE, Dawson EB (1979) Apparent effect of ascorbic acid medication on semen metal levels. Fertil Steril 32(4): 455-459.

[16]. Dawson EB, Harris WA, Powell LC (1990) Relationship between ascorbic acid and male fertility. World Rev Nutr Diet 62: 1-26.

[17]. Dabrowski K, Ciereszko A (1996) Ascorbic acid protects against male infertility in a teleost fish. Experientia 52(2): 97-100.

[18]. Colagar AH, Marzony ET (2009) Ascorbic acid in human seminal plasma: Determination and its relation to sperm quality. J Clin Biochem Nutr 45(2): 144-149.

[19]. Nishikimi M, Yagi K (1991) Molecular basis for the deficiency in humans of gulonolactone oxidase, a key enzyme for ascorbic acid biosynthesis. Am J Clin Nutr 54(6 Suppl): 1203S-1208S.

[20]. Nishikimi M, Fukuyama R, Minoshima S, Shimizu N, Yagi K (1994) Cloning and chromosomal mapping of the human nonfunctional gene for Lgulono-gamma-lactone oxidase, the enzyme for L-ascorbic acid biosynthesis missing in man. J Biol Chem 269(18): 13685-13688.

[21]. Pinnell SR (1985) Regulation of collagen biosynthesis by ascorbic acid: a review. Yale J Biol Med 58(6): 553-559.

[22]. Hulmes DJ (1992) The collagen super family-diverse structures and assemblies. Essays Biochem 27: 49-67.

[23]. Kukucka MA, Misra HP (1992) HPLC determination of an oxytocin-like peptide produced by isolated guinea pig Leydig cells: stimulation by ascorbate. Arch Androl 29(2): 185-190.

[24]. Goralczyk R, Moser UK, Matter U, Weiser H (1992) Regulation of steroid hormone metabolism requires L-ascorbic acid. Ann NY Acad Sci 669: 349351.

[25]. Arrigoni O, De Tullio MC (2002) Ascorbic acid: much more than just an antioxidant. Biochim Biophys Acta 1569(1-3): 1-9.

[26]. Davis MB, Austin J, Partridge DA (1991) Vitamin C: Its Chemistry and Biochemistry. Royal Society of Chemistry, Cambridge.

[27]. Rebouche CJ (1991) Ascorbic acid and carnitine biosynthesis. Am J Clin Nutr 54(6 Suppl): 1147S-1152S.

[28]. Naidu KA (2003) Vitamin C in human health and disease is still a mystery? An overview. Nutr J 2: 7

[29]. Schaffert RR, Kingsley GR (1955) A rapid, simple method for the determination of reduced, dehydro-, and total ascorbic acid in biological material. J Biol Chem 212(1): 59-68.

[30]. Block G, Norkus E, Hudes M, Mandel S, Helzlsouer K (2001) Which plasma antioxidants are most related to fruit and vegetable consumption? Am J Epidemiol 154(12): 1113-1118.

[31]. Joshipura KJ, Hu FB, Manson JE, Stampfer MJ, Rimm EB, et al. (2001) The effect of fruit and vegetable intake on risk for coronary heart disease. Ann Intern Med 134(12): 1106-1114.

[32]. Liu S, Manson JE, Lee IM, Cole SR, Hennekens CH, et al. (2000) Fruit and vegetable intake and risk of cardiovascular disease: the women's health study. Am J Clin Nutr 72(4): 922-928.

[33]. Taniyama Y, Griendling KK (2003) Reactive oxygen species in the vasculature: molecular and cellular mechanisms. Hypertension 42(6): 1075-1081.

[34]. Li Y, Schellhorn HE (2007) New developments and novel therapeutic perspectives for Vitamin C. J Nutr 137(10): 2171-2184.

[35]. Block G (1992) Vitamin C status and cancer. Epidemiologic evidence of reduced risk. Ann N Y Acad Sci 669: 280-290.

[36]. Cadenas E, Packer L (2002) Handbook of antioxidants. (2nd edtn), Marcel Dekker, Inc., New York.

[37]. Carr AC, Zhu BZ, Frei B (2000) Potential antiatherogenic mechanisms of ascorbate (vitamin C) and alpha-tocopherol (vitamin E). Circ Res 87(5): 349-354.

[38]. Chen X, Touyz RM, Park JB, Schiffrin EL (2001) Antioxidant effects of vitamins $\mathrm{C}$ and $\mathrm{E}$ are associated with altered activation of vascular NADPH oxidase and superoxide dismutase in stroke-prone SHR. Hypertension 38(3 Pt 2): 606-611.

[39]. El-Adawy TA, Rahma EH, El-Bedawey AA, El-Beltagy AE (2004) Nutritional potential and functional properties of germinated mung bean, pea and lentil seeds. Plant Foods for Human Nutrition 58(3): 1-13. 